\title{
A Qualitative Study of Barriers to Consistent Condom Use among HIV-1 Serodiscordant Couples in Kenya
}

\author{
Kenneth Ngure ${ }^{a, b,}{ }^{,}$, Nelly Mugo ${ }^{a, c}$, Connie Celum ${ }^{c, d, e}$, Jared M. Baeten ${ }^{c, d, e}$, Martina \\ Morris $^{\mathrm{f}, \mathrm{g}}$, Owuor Olungah ${ }^{\mathrm{h}}$, Joyce Olenja ${ }^{\mathrm{i}}$, Harrison Tamooh ${ }^{\mathrm{a}}$, and Bettina Shell-Duncan ${ }^{\mathrm{j}}$ \\ aDepartment of Obstetrics and Gynaecology, Kenyatta National Hospital, Nairobi, Kenya \\ bInstitute of Tropical Medicine and Infectious Diseases, Jomo Kenyatta University Kenya \\ 'Department of Global Health, University of Washington, Seattle, USA \\ dDepartment of Epidemiology, University of Washington, Seattle, USA \\ eDepartment of Medicine, University of Washington, Seattle, USA \\ fDepartment of Statistics, University of Washington, Seattle, USA \\ gDepartment of Sociology, University of Washington, Seattle, USA \\ hDepartment of Anthropology University of Nairobi, Kenya \\ iDepartment of Community Health, University of Nairobi, Kenya \\ iDepartment of Anthropology, University of Washington, Seattle, USA
}

\section{Abstract}

This study explored barriers to consistent condom use among heterosexual HIV-1 serodiscordant couples who were aware of the HIV-1 serodiscordant status and had been informed about condom use as a risk reduction strategy. We conducted 28 in-depth interviews and 9 focus group discussions among purposively-selected heterosexual HIV-1 serodiscordant couples from Thika and Nairobi districts in Kenya. We analyzed the transcribed data with a grounded theory approach. The most common barriers to consistent condom use included male partners' reluctance to use condoms regardless of HIV-1 status coupled with female partners' inability to negotiate condom use, misconceptions about HIV-1 serodiscordance, and desire for children. Specific areas of focus should include development of skills for women to effectively negotiate condom use, ongoing information on HIV-1 serodiscordance and education on safer conception practices that minimize risk of HIV-1 transmission.

\section{Keywords}

HIV-1; Serodiscordant; Condom use; Kenya

\section{Background}

At the end of 2008, 33.4 million people were living with human immunodeficiency virus type 1 (HIV-1) worldwide (UNAIDS, 2009). In Kenya, 1.3 million adults are infected with HIV-1 (KAIS, 2007). A recent population-based survey estimated that $5.9 \%$ of all married or cohabiting couples in Kenya were in an HIV-1 serodiscordant relationship (i.e., one in

*Corresponding author: Kenyatta National Hospital, Partners in Prevention Project, P. O .Box 19704-00202 Nairobi, Kenya. Tel: +254722362219 k_ngure@ hotmail.com. 
which one partner is HIV-1-infected and the other is HIV-1-uninfected), translating to an estimated 344,000 HIV-1 serodiscordant couples (KAIS, 2007). Multinational studies in sub-Saharan Africa have demonstrated that HIV-1 serodiscordant couples are common (Lingappa et al., 2008; Oghenowede et al., 2010), and prospective studies have reported a high HIV-1 incidence in serodiscordant partnerships (Quinn et al., 2000). Mathematical models have suggested that stable HIV-1 serodiscordant couples may be responsible for a majority of HIV-1 infections in sub-Saharan Africa (Dunkle et al., 2008). Therefore, interventions to prevent HIV-1 transmission in this high risk group may offer substantial public health benefits.

For sexually-active HIV- 1 serodiscordant couples, effective HIV-1 prevention strategies are condoms (Allen et al., 1992; Davis \& Weller 1999) and male circumcision (Auvert et al., 2005). Male condom use has high efficacy for HIV-1 prevention and can also reduce unwanted pregnancies; however, $<5 \%$ of married or cohabiting couples report consistent condom use in Kenya (KAIS, 2007).

African heterosexual couples do not routinely use condoms except after positive HIV-1 test results (KAIS, 2007; Bunnell et al., 2008). Common barriers to condom use reported in prior studies in Kenya and elsewhere include gender inequality (Sarna et al., 2009; Sarkar, 2008), desire for children (Bunnell et al., 2008; Chakrapani et al., 2010; Chersich et al., 2009), and non-disclosure of HIV-1 status (Sarna et al., 2009; Chersich et al., 2009). In this study we investigate barriers to condom use in a specialized population: heterosexual couples who are aware of the HIV-1 serodiscordant status who have been informed about condom use as a risk reduction strategy. It has been widely assumed that serodiscordant couples educated about prevention strategies would be highly motivated to adopt consistent condom use because of their awareness of their high risk of HIV-1 transmission. Consequently, condom use has become a primary HIV-1 prevention strategy for this population. However, it now appears that this group also faces formidable challenges to consistent and correct condom use. The purpose of this study is to identify barriers to condom use among serodiscordant couples, providing crucial information for improving public health intervention efforts aimed at reducing HIV-1 transmission.

\section{Methods}

This was a cross-sectional qualitative study that explored barriers to consistent condom use among HIV-1 serodiscordant couples.

\section{Study Setting}

This study was conducted at the Thika and Nairobi, Kenya, which were sites of the Partners in Prevention HSV/HIV Transmission Study (Lingappa et al., 2009). In depth interviews (IDIs) and focus group discussions (FGDs) were conducted between July 2008 and February 2009.

\section{Study Participants}

Participants we recruited from Thika and Nairobi sites of the Partners in Prevention HSV/ HIV Transmission Study ( 40\%), as well as from AIDS service organizations and post-test clubs in these communities ( $60 \%)$. These organizations provided couples HIV counseling and testing and some including the Partners in Prevention study provided condoms free-ofcharge. Inclusion criteria included the following: in a stable, sexually active couple; both members of a couple had to be $\geq 18$ years of age, aware of their HIV-1 serodiscordancy and willing to participate in this study. Participants were excluded if they were single or had 
separated with their sexual partners. Participants who participated in the IDIs did not participate in the FGDs and vice versa.

\section{Data Collection}

We conducted 28 IDIs and 9 FGDs among individuals in HIV-1 serodiscordant couples; a sample size was adequate based on the principles of qualitative research (Sandelowski, 1995). All interviews were facilitated by a trained and experienced couples' HIV-1 counselor and a trained interview assistant. We used semi-structured interview guides, these allowed for probing and clarification (Bernard \& Ryan, 2010). The IDIs and FGDs lasted on average 60 minutes and 90 minutes respectively. More than half $(60 \%)$ of the interviews were conducted at the research sites while the rest were conducted at mutually agreed offsite venues such as community halls based on participants' preference. IDIs were conducted separately for 12 couples, while 2 couples were interviewed together as per their request. Interviews were conducted in English, Kiswahili or Kikuyu depending on participants' preference in the IDIs and on consensus in the FGDs.

All the interviews were tape recorded and later translated into English (when needed) and transcribed. Prior to coding, 50\% of the transcripts were checked against the audio recording to validate the quality of transcription and translation.

\section{Data Analysis}

We (first author and a trained graduate research assistant) compiled all the qualitative data by gender, HIV-1 status and method of interview. We then read all transcripts as individual wholes to gain an overall understanding of the data and coded the transcripts using ATLAS ti version 6.1.2 software. We used a common inductive approach to coding based on the grounded theory. This allowed us explore the barriers from the participants' point of view what the participants believed rather than testing a pre-existing theory (Strauss \& Cobin, 2008). We then compared the results of our coding for consistency of text segmentation and code application. When the results were acceptable and consistent, the coding continued with periodic checks for continued intercoder agreement. Inconsistent results were reviewed by the coders until a consensus was reached (MacQueen et al., 1998).

\section{Ethical Approval}

We obtained ethical approval for the study from the Kenyatta National Hospital Ethical Review Committee and University of Washington Institutional Review Board. All participants provided written informed consent.

\section{Results}

\section{Participant Characteristics}

We conducted 28 IDIs among individuals in HIV-1 serodiscordant couples as follows: HIV-1 positive women ( $n=7)$, HIV-1 negative women ( $n=7)$, HIV-1 positive men $(n=7)$, HIV-1 negative men $(n=7)$. Nine FGDs were stratified by gender and HIV-1 status as follows: HIV-1 positive women ( $n=2)$, HIV-1 negative women $(n=2), H I V-1$ positive men $(n=3)$ and HIV-1 negative men $(n=2)$. The sociodemographic profile of respondents is shown in Table 1. The median age was 33 and 38 for women and men respectively, and almost all couples were not using condoms prior to testing HIV discordant.

\section{Barriers to condom use}

The results are presented by most salient themes with a few illustrative quotes under each theme to 'amplify' the voices of the participants (Sandelowski, 1998). The sections in the 
results arose naturally out of the discussions when couples were asked to discuss the challenges of living with HIV -1 serodiscordance. Consistent condom use was one of the main challenges of living with HIV-1 serodiscordance due to the barriers discussed herein. Though we have attempted to separate and rank the themes, these themes are highly intertwined and clustered.

1. Male partner's reluctance to use condoms-The most common barrier to consistent condom use was reluctance by male partners to use condoms. There was a consensus among women in IDIs and FGDs that men were reluctant to use condoms, even when the woman was the HIV-1 infected partner. Men in the FGDs corroborated these views. Additionally, women reported having difficulty negotiating condom use. Requesting male partners to use condoms sometimes sparked anger that led to verbal abuse, withholding of economic support, and in extreme cases, physical abuse. Many of the urban couples reported that living in one-room houses contributed to problems with negotiating condom use. Since quarrels regarding condom use usually happened at night, some women were forced to accept sex without a condom to avoid waking up their children and neighbors. Additionally, fear of abandonment, especially among HIV-1 seropositive women, made some of them agree to have sex without condoms.

One of the main reasons for male partner's reluctance to use condoms was reduced sexual pleasure. A majority reporting not feeling "sexually satisfied" when they used condoms. Additionally, some female participants feared that their male partners would go out to seek new partners so that they could have sex without a condom. To prevent this from happening, some women agreed to sex without a condom.

Alcohol use was also reported as a common cause of men's inconsistent use condoms, with men reporting that they did not know what happened when they got drunk. Alcohol use was more commonly reported as a barrier by urban couples than couples from more rural settings. Women reported that it was harder to negotiate condom use when their male partners had used alcohol, as this increased the risk of verbal and physical abuse. Most women in the FGDs suspected that men sometimes pretended to be drunk so that they could avoid using condoms. Failure to use condoms was usually followed by feelings of guilt and regret, especially by the HIV-1 seronegative partners.

2. Misconceptions about HIV-1 discordance-All study participants could correctly define HIV-1 serodiscordance as 'different HIV-1 status between members of a couple.' However, deeper understanding of HIV-1 serodiscordance was often lacking. Common misconceptions included HIV-1 negative men thinking that they were 'immune' to HIV-1 infection, couples believing that God would protect the negative partner from HIV-1 and some couples questioning the validity of their serodiscordant HIV-1 tests because they had previously not used condoms in their relationship. Notably couples who were recruited from outside the Partners in Prevention the Partners HSV/HIV Transmission Study reported more misconceptions and attributed some of the misconceptions to health workers and HIV-1 counselors.

A common statement in IDI and FGDs related to the community assumption that men were promiscuous and women were faithful. As a result, HIV-1 seronegative men often assumed that their female partners had become infected before they were married, which made them to believe that the risk of acquiring HIV-1 from their partners was minimal, this reduced their motivation to use condoms consistently.

In contrast, HIV-1 seronegative women reportedly believed their seropositive male partners had acquired HIV during their marriage through a concurrent, extramarital sexual 
partnership, which motivated women to use condoms. Interestingly, a few HIV-1 positive women reportedly thought they had been infected by their HIV-1 negative male partners, who transmitted HIV-1 to them without the male becoming HIV-1 infected. The refusal by HIV-1 seronegative men to use condoms despite knowing that their female partners were HIV-1 seropositive reinforced this misconception.

Another misconception was having sexual intercourse without using condoms in the beginning of the intercourse, and putting on the condom just before ejaculation. The request to do this was made by a few men, and their female partners agreed under the mistaken belief that HIV-1 transmission could only occur if the male partner ejaculated.

Notably, most of the misconceptions occurred after a few weeks of condom use, suggesting condom fatigue.

3. Desire for Children-Most of the study participants that desired children reported that consistent condom use was a barrier to having children. Many serodiscordant couples reported that having additional children was one of the biggest challenges of living with HIV-1 discordance. Some participants were unaware that there are safer alternatives to unprotected sex for getting pregnant such as artificial insemination. Among the couples that knew about these alternatives, a number of couples held negative views.

4. Lack of adequate knowledge on condom use-Most of the couples reported using condoms for the first time after testing HIV-1 discordant and being told by the HIV-1 counselors to use them. Women in particular reported frequent condom breakages ('bursts'), and this was viewed as a normal occurrence. This made some participants to feel that they had little control over their risk of HIV-1 acquisition.

Sometimes condom breakages resulted from practices such as wiping lubricant from condoms before sex. This practice was reportedly done to increase sexual pleasure. Two women claimed that condom breakage was resulted in an unplanned pregnancy. HIV seronegative women and men both reported using substances such as bleach or hot water and soap to clean themselves after condom breakage or after unprotected intercourse in the hope of preventing HIV-1 acquisition.

5. Non-disclosure of HIV-1 status-When couples tested separately, they took time, ranging from days to years, before disclosing their HIV-1 seropositive results to their sexual partners. Non-disclosure of HIV status by both men and women hindered initiation and consistence of condom use. One participant reported using antiretroviral medications secretly, before disclosing his HIV-1 seropositive status. Additionally, when some HIV-1 seropositive individuals had new sexual partners, they did not disclose their HIV-1 test results immediately for fear of losing their new partner. Participants also expressed lack of skills to disclose results to their sexual partners for fear of being blamed.

\section{Discussion}

Despite awareness of their HIV-1 serodiscordant status and risk reduction strategies, a vast majority of persons experience numerous barriers to consistent condom use, irrespective of their gender or HIV-1 status. These barriers to condom use are highly interrelated, suggesting that interventions to increase condom use among HIV-1 serodiscordant couples need to be packaged in a way to address these intertwined concerns.

In our study, there was a consensus among both men and women that men were more reluctant to use condoms, even when their female partner was HIV-1 seropositive. This was 
a surprising finding, because we had expected that HIV-1 seronegative men would be motivated to use condoms to prevent HIV-1 acquisition. One of the key assumptions of cognitive behavior change models is that individuals educated about risks will be motivated to change their behaviour in the desired direction. Behavior change research has, however, called this assumption into question, noting that people may have valid reasons for not complying with advice on risk reduction, and may have other factor constraining or motivating their behaviour (Ingham et al., 1992; Parker, 2004).

Additionally, women reported difficulties in negotiating condom use, making HIV-1 seronegative women in particular feel helpless. Requests by women for men to use condoms sometimes sparked anger that led to men withholding economic support, as well as verbal and physical abuse. Gender inequality has been reported to be a barrier to condom use in many studies (Sarkar, 2008). In cognitive models, "most social behavior is assumed to be based on volition, and very closely linked to intention to perform that behaviour" (Yoder, 1997). Yet for sexual encounters, this may not be the case since sexual negotiation is not necessarily between equals (Yoder, 1997; Davis \& Sigma, 1992). Instead, there are situations in which one individual has more power to decide the course of events than the other, and this decision-making power is not fixed over time, but continuously renegotiated, even between the same two individuals (Davis \& Sigma, 1992).

In our study reduced sexual pleasure was reported as a key reason for male partners' reluctance to use condoms, this is consistent with other studies of male condom use, (Chakrapani et al., 2010). In addition alcohol use by the male partners was significant cause of lapses in condom use, although there were contradicting views between men and women on the effects of alcohol on condom use. Alcohol use has been linked to HIV-1 risk in previous studies as well (Sarkar, 2008; Chakrapani et al., 2010; Chersich et al., 2009; Kalichman et al., 2007).

Misconceptions about HIV discordance were common in our study which led to low perception of risk of both HIV-1 acquisition and transmission which consequently led to poor adherence to condom use. Although this finding was consistent with other studies (Bunnell et al., 2005), our study shows that there are gender differences in the misconceptions. Additional research about multiple rationalities and misconceptions influencing use of condom among HIV-1 serodiscordant couples may be informative.

In Africa, child bearing is an important social milestone for couples. Although a majority of the participants in our study had two or more children, many still reported a desire for more children. Couples therefore viewed consistent condom use as a barrier to reaching their preferred family size. Similarly, studies conducted among HIV-1 seropositive women and men in Kenya, Uganda and India found that a desire for children posed a barrier to condom use (Sarna et al., 2009; Bunnell et al., 2008; Chakrapani et al., 2010).

The strengths of our study include the interviews of both members of HIV-1 serodiscordant couples. We used both IDIs and FGDs in a complementary manner to validate the findings. Separation of couples during IDIs provided a greater range of responses, which may have been particularly useful for our population, given high levels of gender inequality in Kenya.

This study has a number of limitations, including that we recruited from former clinical trial participants in an HIV-1 prevention trial and from community-based organizations. These programs provided condoms and counseling, which may reduce generalization of the findings to other HIV-1 serodiscordant couples in the community who have not received similar, couples HIV-1 counseling and testing. The counselor who facilitated the interviews had provided couples HIV-1 counseling to some of the participants at Thika Site, which may have limited responses from some couples. Additional larger studies replicating these results 
would increase the reliability of our findings and provide additional evidence to guide interventions to increase condom use among HIV-1 serodiscordant couples.

\section{Conclusions}

In summary, our study was able to identify common barriers to consistent condom use specifically among HIV-1 serodiscordant couples in Kenya who had disclosed their status to one another, and had received information on HIV-1 prevention strategies. These barriers should inform intervention efforts, with the aim of increasing the consistency in condom use among HIV-1 serodiscordant couples. Specific areas of support include equipping women with skills to negotiate safe condom use and increasing access to acceptable female controlled methods. Further, education about HIV-1 discordance to dispel misconceptions, information on safe and effective ways of childbearing for couples who desire children, skills on effective condom use (e.g. demonstrations of condom use) and training on disclosure of HIV-1 positive status to new sexual partners should to be incorporated into the counseling of HIV-1 serodiscordant couples. The proposed interventions should be provided at the initial counseling session in which the couple learns of their HIV-1 serodiscordant results and in ongoing couples-centered counseling.

\section{Acknowledgments}

We are thankful to the study participants for this qualitative study. Special thanks to Dr. James Pfeiffer for assisting in shaping of this manuscript during the initial stages. We are grateful to John Njoroge and Sophie Vusha for conducting and transcribing the interviews. We thank the principal investigators (Drs. James Kiarie, Carey Farquhar and Grace John-Stewart) at the Nairobi site for the Partners in Prevention HSV/HIV Transmission Study. This research was funded by NIH grants R24 HD056799 and R01 AI083034 and by the University of Washington Center for AIDS Research (CFAR), an NIH funded program (P30 AI027757) which is supported by NIAID, NCI, NIMH, NIDA, NICHD, NHLBI, NCCAM. Kenneth Ngure was a scholar in the International AIDS Research and Training Program, supported by the Fogarty International Center, NIH Research Grant D43 TW000007.

\section{References}

Allen S, Tice J, Van de Perre P, Serufilira A, et al. Effect of serotesting with counseling on condom use and seroconversion among HIV-1 discordant couples in Africa. BMJ. 1992; 304(6842):16051609. [PubMed: 1628088]

Auvert B, Taljaard D, Lagarde E, Sobngwi-Tambekou J, Sitta R, et al. Randomized, Controlled Intervention Trial of Male Circumcision for Reduction of HIV Infection Risk: The ANRS 1265 Trial. PLoS Med. 2005; 2(11):e298. [PubMed: 16231970]

Bernard, HR.; Ryan, G. Analyzing Qualitative Data: Systematic Approaches. Thousand Oaks, CA: Sage Publications; 2010.

Bunnell R, Opio A, Musinguzi J, Kirungi W, et al. HIV-1 transmission risk behavior among HIV-1infected adults in Uganda: results of a nationally representative survey. AIDS.12. 2008; 22(5):617624.

Bunnell ER, Nassozi J, Marum E, Mubangizi J, et al. Living with discordance: knowledge, challenges, and prevention strategies of HIV-discordant couples in Uganda AIDS Care: Volume 17. 2005; (Issue 8):999-1012.

Chakrapani V, Newman PA, Shunmugam M, Dubrow R. Prevalence and contexts of inconsistent condom use among heterosexual men and women living with HIV-1 in India: implications for prevention. AIDS Patient Care STDS. 2010; 24(1):49-58. [PubMed: 20095889]

Chersich MF, Rees HV, Scorgie F, Martin G. Enhancing global control of alcohol to reduce unsafe sex and HIV-1 in sub-Saharan Africa. Global Health. 17. 2009; 5:16.

Davis KR, Weller SC. The effectiveness of condoms in reducing heterosexual transmission of HIV-1. Fam Plann Perspect. 1999; 31(6):272-279. [PubMed: 10614517] 
Davies, P.; SIGMA, P. On relapse: Recidivism or rational response?. In: Aggelton, P.; Davies, P.; Hart, G., editors. AIDS: Rights, Risk and Reason. Washington D.C.: The Falmer Press; 1992. p. 133-141.

Dunkle KL, Stephenson R, Karita E, Chomba E, Kayitenkore K, Vwalika C, et al. New heterosexually transmitted HIV-1 infections in married or cohabiting couples in urban Zambia and Rwanda: an analysis of survey and clinical data. Lancet. 2008; 371:2183-2191. [PubMed: 18586173]

Ingham, R.; Woodcock, A.; Stenner, K. The limitations of rational decision-making models as applied to young people's sexual behaviour. In: Aggleton, P.; Davies, P.; Hart, G., editors. AIDS: Rights, Risk and Reason. Washington, D.C.: The Falmer Press; 1992. p. 163-173.

Kalichman SC, Simbayi LC, Kaufman M, Cain D, Jooste S. Alcohol use and sexual risks for HIV-1/ AIDS in sub-Saharan Africa: systematic review of empirical findings. Prev Sci. 2007; 8(2):141151. Epub 2007 Jan 31. [PubMed: 17265194]

Lingappa JR, Lambdin B, Bukusi EA, Ngure K, Kavuma L, Inambao M, et al. Regional differences in prevalence of HIV-1-1 discordance in Africa and enrollment of HIV-1-1 discordant couples into an HIV-1-1 prevention trial. PLoS ONE. 2008; 3:e1411.

Lingappa JR, Kahle E, Mugo N, Mujugira A, Magaret A, Baeten J, et al. Characteristics of HIV-1 discordant couples enrolled in a trial of HSV-2 suppression to reduce HIV transmission: The Partners Study. PLoS ONE. 2009; 4:e5272. [PubMed: 19404392]

Sandelowski M. Writing a good read: Strategies for re-presenting qualitative data. Research in Nursing \& Health. 21:375-382. 199.

MacQueen KM, McLellan E, Kay K, Milstein B. Codebook development for team-based qualitative analysis. Cultural Anthropology Methods. 1998; 10(2):31-36.

National AIDS and STI Control Program (NASCOP), Ministry of Health (MOH), Kenya. Kenya AIDS Indicator Survey 2007: Preliminary Report. Nairobi, Kenya: Republic of Kenya; 2008.

Oghenowede E, Damien W, Nathan F, Gloria G, Richard TL, Edward JM. HIV status in discordant couples in sub-Saharan Africa: a systematic review and meta-analysis. 2010 www.thelancet.com/ infection Published online OI: 10.1016/S1473-3099(10)70189-4.

Parker, W. Rethinking conceptual approaches to behavior change: The importance of context. Centre for AIDS Development, Research and Evaluation (CADRE); 2004.

20. Quinn TC, Wawer MJ, Sewankambo N, Serwadda D, Li C, Wabwire-Mangen F, Meehan MO, Lutalo T, Gray RH. Viral load and heterosexual transmission of human immunodeficiency virus type 1. Rakai Project Study Group. N Engl J Med. 30. 2000; 342(13):921-929.

Sandelowski M. Sample size in qualitative research. Research in nursing \& health. 1994; 18:179-183. [PubMed: 7899572]

Sarna A, Chersich M, Okal J, Luchters SM, Mandaliya KN, Rutenberg N, Temmerman M. Changes in sexual risk taking with antiretroviral treatment: influence of context and gender norms in Mombasa, Kenya Cult Health Sex. 2009 Nov; 11(8):783-797.

Sarkar NN. Barriers to condom use. Eur J Contracept Reprod Health Care. 2008; 13(2):114-122. [PubMed: 18465472]

Shrier LA, Walls C, Lops C, Feldman HA. Correlates of Incorrect Condom Use among Depressed Young Women: An Event-level Analysis. J Pediatr Adolesc Gynecol. 2010 (Epub ahead of print).

Strauss, A.; Corbin, J. Basics of Qualitative Research: Techniques and Procedures for Developing Grounded Theory. 3rd ed.. Thousand Oaks, CA: Sage Publications; 2008.

UNAIDS. Report on the global AIDS epidemic. Geneva: UNAIDS; 2009.

Yoder PS. Negotiating relevance: Belief, knowledge, and practice in international health projects. Medical Anthropology Quarterly. 1997; 11:131-146.

Yoder PS. From sexual behavior to sexual encounters: Issues in AIDS prevention research. Reviews in Anthropology. 2001; 30:225-241. 
Table 1

Sociodemographic Information

\begin{tabular}{|c|c|c|c|c|}
\hline \multirow[t]{2}{*}{ Characteristic } & \multicolumn{2}{|l|}{ IDIs } & \multicolumn{2}{|l|}{ FGDs } \\
\hline & Males $n=14$ & Females n=14 & Males $n=34$ & Females $n=27$ \\
\hline \multicolumn{5}{|l|}{ Age in groups } \\
\hline $20-24$ & 0 & 1 & 2 & 1 \\
\hline $25-29$ & 3 & 2 & 4 & 7 \\
\hline $30-34$ & 2 & 8 & 4 & 5 \\
\hline $35-39$ & 3 & 3 & 8 & 7 \\
\hline $40-44$ & 6 & 0 & 4 & 1 \\
\hline $45-49$ & 0 & 0 & 8 & 4 \\
\hline $50 \&$ Over & 0 & 0 & 4 & 2 \\
\hline \multicolumn{5}{|l|}{ HIV Status } \\
\hline Positive & 7 & 7 & 20 & 14 \\
\hline Negative & 7 & 7 & 14 & 13 \\
\hline \multicolumn{5}{|l|}{ No. of children } \\
\hline 0 & 0 & 0 & 2 & 1 \\
\hline 1 & 3 & 3 & 5 & 8 \\
\hline 2 & 2 & 4 & 10 & 10 \\
\hline $3 \&$ more & 9 & 7 & 17 & 8 \\
\hline \multicolumn{5}{|l|}{ Source of Couples } \\
\hline Rural & 7 & 7 & 18 & 13 \\
\hline Urban & 7 & 7 & 16 & 14 \\
\hline
\end{tabular}


Table 2

Illustrative Quotes

\begin{tabular}{|c|c|c|}
\hline & Theme & Quotes \\
\hline 1 & $\begin{array}{l}\text { Male partners reluctance } \\
\text { to use condoms. }\end{array}$ & $\begin{array}{l}\text { "He refuses to use a condom, and you want him to use it, so he finds a way of getting out. When he finds his } \\
\text { way, he will not leave money for food. You will only eat when he decides, even if you stay for a week. He } \\
\text { will be coming and going to the bed straight away. He will say you refused and yet you know the } \\
\text { consequence." HIV-1 seropositive female, age } 37 \text { (FGD) } \\
\text { "So when having sex with your wife and you have not used a condom, now that you are HIV positive you } \\
\text { will want to continue that way you wouldn't want to use the condom." HIV-1 seropositive male, age } 35 \\
\text { (FGD). } \\
\text { "It is a problem because he does not want to use, but you want him to use because you know the problem. } \\
\text { Therefore, if you refuse to have sex without it, he might leave. So condom contributes to the problem." } \\
\text { HIV-1 seropositive female, age } 40 \text { (FGD). } \\
\text { "When I went to the VCT I was given around } 100 \text { condoms. I tried to use for } 3 \text { days and I felt I did not get } \\
\text { the satisfaction that I wanted. I tried and for some time I felt tired and I did not do any 'job' so I told my } \\
\text { wife there was no need. If we had sex for six years and you did not infect me, we will not use the condoms. } \\
\text { We shall give them out." HIV-1 seronegative male, age } 39 \text { (IDI). } \\
\text { "It is the same way, at times he uses and others he does not want, especially when he is drunk if you tell } \\
\text { him about the condom he can hit you." HIV-1 seronegative female, age } 32 \text { (FGD). } \\
\text { "Then you decide now there I will take alcohol, then you would find me when I have taken alcohol that is } \\
\text { when I mess because when I reach there I forget even the condom because I want it very fast. So now by the } \\
\text { time you are disagreeing you find that you have already finished. After that, that is when you start thinking } \\
\text { about being infected. That is when you start regretting - after finishing; you ask yourself these few minutes } \\
\text { will make me ruin my life." HIV-1 seronegative male, age } 26 \text { (FGD). }\end{array}$ \\
\hline 2 & $\begin{array}{l}\text { Misconceptions about } \\
\text { HIV-1 discordance. }\end{array}$ & $\begin{array}{l}\text { "Yes, we were having unprotected sex since I married her in 1994, and knew her status in 2000. Until now, } \\
\text { I do not use protection. We continue with life the normal way, though she is on drugs (HIV medicines). I } \\
\text { told my wife, if you have the virus try to be faithful because if you get another virus it will kill me. However, } \\
\text { the ones you have, have been defeated with my blood.." HIV-1 seronegative male, age } 36 \text { (IDI). } \\
\text { "You see some may resist using the condoms initially but later they adopt the use. Sometimes there are even } \\
\text { disagreements. For instance look at our support group the number of women with children has increased. } \\
\text { When you talk to the women they will tell you how difficult it has been. The women claim that the husbands } \\
\text { insist that even before they knew their status they were never using condoms. Therefore, they will not use } \\
\text { them. Hence, many have become pregnant. It is challenging to use condoms." HIV-1 seronegative female, } \\
\text { age } 36 \text { (IDI). } \\
\text { "He was advised to use the condom, the funny thing is he does not use, he says before I tested I was not } \\
\text { using the condom. He tells me I will not use that condom. I am not using it. Before you didn't know there } \\
\text { was a condom in this world, you have just known it recently, so you do not know how long we haven't used } \\
\text { it and now you are insisting. " HIV-1 seropositive female, age } 33 \text { (IDI). } \\
\text { "I tell him to use the condom, I keep insisting... That is what disturbs me, I always think maybe my partner } \\
\text { has the virus and he might be infecting me with his virus." HIV-1 seropositive female, age } 32 \text { (IDI). } \\
\text { "There are several people I know who have refused to use condoms. They claim the husband refused to use } \\
\text { the condom, yet he knows she is infected. I asked her why and she said he told her whenever she dies they } \\
\text { will die together. They even got a baby." HIV-1 seronegative female, age } 34 \text { (IDI). }\end{array}$ \\
\hline 3 & Desire for Children & $\begin{array}{l}\text { "I would want to have a baby and we have stayed for long and we are not getting one. Moreover, even in } \\
\text { my prayer I always mention the baby. I want to have the baby with the one I have stayed with. I do not want } \\
\text { to get the baby from someone else so you find it is like that. I might put on the condom and that is the day } \\
\text { God has prepared for me to have the child." HIV-1 seronegative male, age } 25 \text { (FGD). } \\
\text { "Yes it has changed because even if I wanted to name my sisters and brothers I can't do that now. I cannot } \\
\text { risk getting the virus because even though this last born of mine. It is by God's mercy that I did not get the } \\
\text { virus. I got to a dead end." HIV -1 seronegative female, age } 36 \text { (IDI) } \\
\text { "When using a condom you will not get a baby. However, when you get that baby through that syringe the } \\
\text { act that the baby was gotten through will not come out of your head. It is like I marry a wife and she goes to } \\
\text { the hospital and gets a small child to adopt, even when the child grows up you will always remember you } \\
\text { got it from the hospital." HIV-1 seropositive male, age } 42 \text { (FGD). }\end{array}$ \\
\hline 4 & $\begin{array}{l}\text { Lack of adequate } \\
\text { knowledge on condom } \\
\text { use }\end{array}$ & $\begin{array}{l}\text { "I had not used the condom before and I am now forced to use. It was my first time to see when we were } \\
\text { tested it apart from hearing it on the radio." HIV-1 seronegative male, age } 43 \text { (IDI). }\end{array}$ \\
\hline
\end{tabular}




\begin{tabular}{|c|c|c|}
\hline & Theme & Quotes \\
\hline & & $\begin{array}{l}\text { "You can have condom burst and that's normal, you may be enjoying sex and the condom bursts you know } \\
\text { you can't control sexual intercourse. You keep doing and you find the condom has burst and that is normal. } \\
\text { Condom burst is normal I cannot be sure that forever I will be negative." HIV-1 seronegative female, age } \\
30 \text { (FGD). } \\
\text { "I told him to wear a condom and I told him to wipe all the lubrication. We started having sex my period } \\
\text { days were bad and I was not on family planning method because we were using condoms. The condom } \\
\text { bursted inside me and he did not feel it until he removed it. I told him that meant HIV and a baby. He said } \\
\text { that was HIV without a baby. I told him my days were bad and we were told to use condoms I was not on } \\
\text { family planning. I stayed for one month and decided to go for a pregnancy test. The test showed I was } \\
\text { pregnant." HIV-1 seronegative female, age } 37 \text { (IDI). } \\
\text { "When the condom bursts you feel the virus has entered you. So you take water and soap to wash it (penis) } \\
\text { thoroughly even with cold water until it shrinks that is when you get satisfied." HIV-1 seronegative male, } \\
\text { age } 26 \text { (FGD). } \\
\text { "He told me to be using a little of jik (bleach) then I put in on a clean cloth and it is the one I will be using } \\
\ldots \ldots . . . v e n \text { if when he fills me even those waters (semen) ........he knows I will get out and go to the } \\
\text { bathroom to use warm water...... and when I leave he knows what I have gone to do." HIV-1 seronegative } \\
\text { female, age } 39 \text { (FGD). } \\
\text { "My husband had refused to use the condom saying that let me go in first without the condom and when I } \\
\text { am almost ejaculating I will put on the condom, you know it has been long, I have forgotten how it feels } \\
\text { without a condom." HIV-1 seronegative female, age } 30 \text { (FGD). }\end{array}$ \\
\hline 5 & $\begin{array}{l}\text { Non-disclosure of HIV-1 } \\
\text { status }\end{array}$ & $\begin{array}{l}\text { We used condoms only on that day. I did not tell her about my status. I feared she would reject me and } \\
\text { escape. We stayed for one month, and then we got married. I was not able to disclose my HIV status. I told } \\
\text { her I had a wife and she died. She became pregnant, I wanted her to go to the clinic, I knew by doing that } \\
\text { she will know her HIV status; she stayed for about } 8 \text { months before attending the clinic." HIV-1 } \\
\text { seropositive male, age } 40 \text { (IDI). } \\
\text { "It happens a lot, like me I knew my status in 1998, I went alone and did not tell my partner, I stayed for a } \\
\text { about } 5 \text { years every time I went to the clinics, I was educated and told to use the condom and I used to } \\
\text { wonder how I will tell him to use it, I only came to tell him after } 5 \text { years which was bad." HIV-1 } \\
\text { seropositive female, age } 26 \text { (FGD). }\end{array}$ \\
\hline
\end{tabular}

